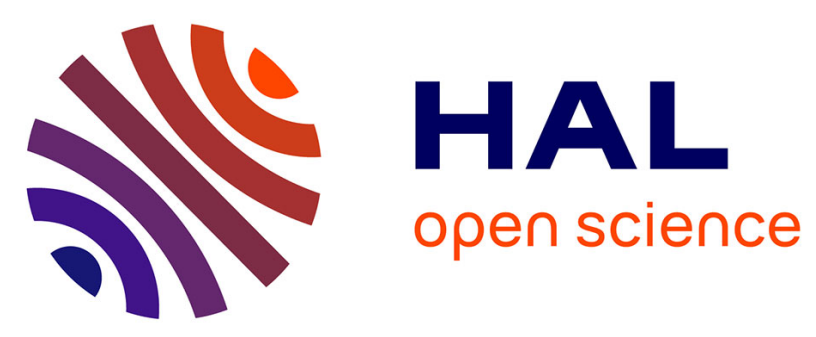

\title{
Study of the negative thermal expansion of cuprite-type structures by means of temperature-dependent Pair Distribution Function analysis: Preliminary results
} Monica Dapiaggi, Hyunjeong Kim, Emil S. Božin, Simon J.L. Billinge, Gilberto Artioli

\section{To cite this version:}

Monica Dapiaggi, Hyunjeong Kim, Emil S. Božin, Simon J.L. Billinge, Gilberto Artioli. Study of the negative thermal expansion of cuprite-type structures by means of temperature-dependent Pair Distribution Function analysis: Preliminary results. Journal of Physics and Chemistry of Solids, 2009, 69 (9), pp.2182. 10.1016/j.jpcs.2008.03.030 . hal-00551216

\author{
HAL Id: hal-00551216 \\ https://hal.science/hal-00551216
}

Submitted on 3 Jan 2011

HAL is a multi-disciplinary open access archive for the deposit and dissemination of scientific research documents, whether they are published or not. The documents may come from teaching and research institutions in France or abroad, or from public or private research centers.
L'archive ouverte pluridisciplinaire $\mathbf{H A L}$, est destinée au dépôt et à la diffusion de documents scientifiques de niveau recherche, publiés ou non, émanant des établissements d'enseignement et de recherche français ou étrangers, des laboratoires publics ou privés. 


\section{Author's Accepted Manuscript}

Study of the negative thermal expansion of cupritetype structures by means of temperature-dependent Pair Distribution Function analysis: Preliminary results

Monica Dapiaggi, HyunJeong Kim, Emil S. Božin, Simon J.L. Billinge, Gilberto Artioli

PII: $\quad$ S0022-3697(08)00099-1

DOI: $\quad$ doi:10.1016/j.jpcs.2008.03.030

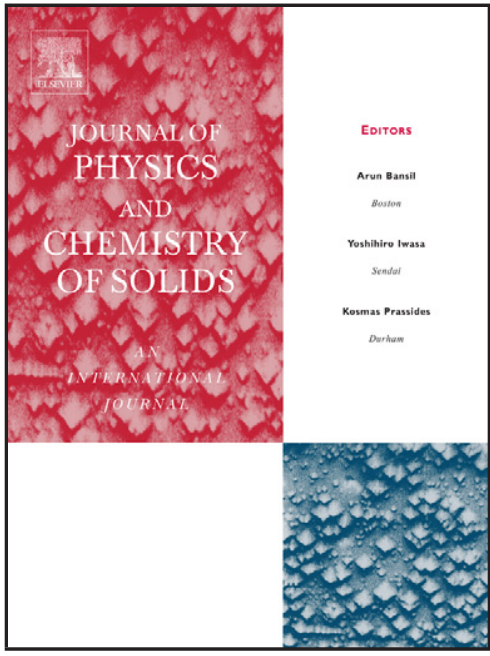

www.elsevier.com/locate/jpcs

Reference: $\quad$ PCS 5430

To appear in: Journal of Physics and Chemistry of Solids

Cite this article as: Monica Dapiaggi, HyunJeong Kim, Emil S. Božin, Simon J.L. Billinge and Gilberto Artioli, Study of the negative thermal expansion of cuprite-type structures by means of temperature-dependent Pair Distribution Function analysis: Preliminary results, Journal of Physics and Chemistry of Solids (2008), doi:10.1016/j.jpcs.2008.03.030

This is a PDF file of an unedited manuscript that has been accepted for publication. As a service to our customers we are providing this early version of the manuscript. The manuscript will undergo copyediting, typesetting, and review of the resulting galley proof before it is published in its final citable form. Please note that during the production process errors may be discovered which could affect the content, and all legal disclaimers that apply to the journal pertain. 


\title{
Study of the negative thermal expansion of cuprite-type structures by means of temperature-dependent Pair Distribution Function analysis: preliminary results
}

M onica Dapiaggi ${ }^{1 *}$, Hyun eong Kim², Emil S. Božinn ${ }^{2}$ Simon J.L. Billinge², Gilberto Artioli

${ }^{1}$ Università degli Studi di M ilano, Dipartimento di Scienze della Terra, via B otticelli 23, I20133 M ilano, Italy

${ }^{2}$ M ichigan State U niversity, D epartment of Physics and A stronomy, East L ansing, M ichigan 48824-1116, USA

${ }^{3}$ U niversità degli Studi di Padova, Dipartimento di Geoscienze, via Giotto 1, 135137 Padova, Italy

*corresponding author, tel. +39-02-50315576, fax. +39-02-50315597, email: monica.dapiaggi@ unimi.it

\begin{abstract}
Copper (I) and silver (I) oxides crystallize with the same structure, and both show a wide range of Negative Thermal Expansion (NTE): $\mathrm{Cu}_{2} \mathrm{O}$ contracts with temperature up to about $200 \mathrm{~K}$ and then expands, while $\mathrm{A}_{2} \mathrm{O}$ has a NTE up to its decomposition temperature at about $450 \mathrm{~K}$. Here we report a careful temperature dependent Pair D istribution Function (PDF) analysis that showed that copper oxide, at about $200 \mathrm{~K}$, exhibits geometric distortions of the tetrahedral units, probably related to a change in the solid angle of the polyhedra. Silver oxide, on the other hand, showed the same distortions even at the lowest temperature
\end{abstract}


measured $(10 \mathrm{~K})$ : structural refinements of the PDF confirmed the presence of local distortions (below $10 \AA$ ) at all temperatures.

Keywords: D-negative thermal expansion, A-silver and copper oxides, C-neutron scattering, Ddefects

\section{Introduction}

The simple cuprite structure is shared by cuprite $\left(\mathrm{Cu}_{2} \mathrm{O}\right)$ and silver $(\mathrm{I})$ oxide $\left(\mathrm{Ag} \mathrm{g}_{2} \mathrm{O}\right)$ and it can be described by two interpenetrated chains of corner sharing $\mathrm{M}_{4} \mathrm{O}$ tetrahedra, where $\mathrm{M}$ represents the metal atom. B oth compounds show a wide range of negative thermal expansion (NTE): cuprite contracts with temperature up to about $200 \mathrm{~K}$ and then expands (but extremely slowly), while $\mathrm{Ag}_{2} \mathrm{O}$ has an NTE up to its decomposition temperature at about $450 \mathrm{~K}$. These materials have been investigated extensively by coupling the anisotropic displacement parameters (ADPS) measured by diffraction to an accurate EXAFS analysis of higher order cumulants in the whole accessible temperature range (for the latest results see references [1] and [2]). The tetrahedral units in the structure proved to be much stiffer against stretching than against bond-bending distortions that bring the metal atoms tow ards each other. The bridging metal atoms show a strong anisotropy in thermal vibrations, larger in the direction perpendicular to the bond than parallel to it. $M$ any of the negative thermal expansion materials have a similar anisotropy in the measured anisotropic displacement parameters, indicating the presence of low-frequency rigid unit modes (RUM S) that can cause rotations of the polyhedral units but that keeps them rigid. In many framework structures, such as $\mathrm{ZrW}_{2} \mathrm{O}_{8}$ (NTE from 0.3 to $1050 \mathrm{~K}$ ) [3], RUM s are thought to be the origin of NTE, though the full 
situation may be more complex [4], [5]. In other framework structures the correlation betw een RUM s and transverse atomic motion cannot be clearly recognized, even though transverse vibrations of bridging atoms surely play a relevant role in NTE. The cuprite structure is one of the latter: the bridging atoms show a strong anisotropy in thermal motion, but the structure shows a complex local behavior of the metal atoms, with a positive thermal expansion of M-O bonds, coupled with a negative thermal expansion of only 6 of the 12 second nearest neighbors (M-M) [2]. Up to now, no simple model was found to explain NTE in these materials. There are many factors that can influence their thermal behavior. A lthough most of them are certainly of vibrational origin, an influence of geometric distortions on NTE cannot be excluded. The presence of static disorder in $\mathrm{Ag}_{2} \mathrm{O}$ [1] was al ready demonstrated by the large intercept at $0 \mathrm{~K}$ of ADPs determined from diffraction. On the other hand, $\mathrm{Cu}_{2} \mathrm{O}$ showed no static disorder whatsoever (the intercept at $0 \mathrm{~K}$ was comparable with zero point motion [6]). All these results suggest the necessity of studying geometric distortions in the cuprite structure. Here we report preliminary results from a temperature dependent Pair Distribution Function (PDF) analysis. The PDF analysis based on total scattering approach was chosen due to the possibility of studying structural distortions at short range as well as at long range, even though they are not detectable with crystallographic techniques. M oreover, PDF results can be compared directly with EXAFS results, allowing the use of these techniques in a complementary and critical way.

This paper aims to present the preliminary data obtained from PDF analysis and to insert them in the scientific background of negative thermal expansion materials. 


\section{Experiments and data reduction}

Total scattering neutron diffraction experiments were performed at the beamline GEM at ISIS (Rutherford A ppleton Laboratory, Chilton, UK) [7], with a cryofurnace, from 10 to $375 \mathrm{~K}$ every $25 \mathrm{~K}$ for $\mathrm{Ag}_{2} \mathrm{O}$ and up to $300 \mathrm{~K}$ every $50 \mathrm{~K}$ for $\mathrm{Cu}_{2} \mathrm{O}$. Commercially available $\mathrm{Cu}_{2} \mathrm{O}$

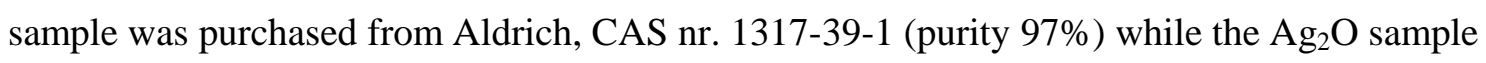
was obtained from Riedel-de-Haën, CA S nr. 20667-12-3 (purity 99.5\%). The $\mathrm{Ag}_{2} \mathrm{O}$ sample did not show any sign of the phase transition observed in other $\mathrm{Ag}_{2} \mathrm{O}$ samples [8], [9]. A high purity vanadium rod, extruded vanadium container, and the sample environment were also collected in order to correct and the normalize the data [10]. A t each temperature data were collected for about 5 hours. The nominal maximum $Q$ attainable at GEM is about $100 \AA^{-1}[7]$. However, the data were used up $Q \max =40 \AA^{-1}$ for $\mathrm{Cu}_{2} \mathrm{O}$, and only up to $\mathrm{Q}=20 \AA^{-1}$ for $\mathrm{Ag}_{2} \mathrm{O}$; the reason for the latter is that data statistics did not allow the use of the high Q range data. A lthough a longer acquisition time might have solved the problem, the experimental decision was to collect as many temperatures as possible in order to have a detailed temperature dependence. Data reduction was performed with the software PDFG etN [11]. Data analyses and simulations were carried out with the softwares PDF fit2 and PDF gui [12]. However, when the two compounds are compared directly a Q max of $20 \AA^{-1}$ was used for both of them in order to obtain a fair assessment of their differences or similarities

\section{Cuprite structure and its PDF peaks}

The cuprite structure is fairly simple, although shared only by two materials: $\mathrm{Cu}_{2} \mathrm{O}$ and $\mathrm{Ag}_{2} \mathrm{O}$. It belongs to space group $P n \overline{3} m$, with the metal (M) atoms occupying the positions $4 \mathrm{~b}$ ) and the oxygen atoms occupying the positions 2a). The cuprite structure is made by two 
interpenetrating lattices, one face centered cubic (FCC) sublattice of metal atoms and one body centered cubic (BCC) sublattice of oxygen atoms. Each M atom is linearly coordinated to two 0 atoms, while each 0 atom is tetrahedrally coordinated to four $\mathrm{M}$ atoms.

A Iternatively, the cuprite structure can be considered as a framew ork of two interpenetrating networks of corner shared $\mathrm{M}_{4} \mathrm{O}$ tetrahedra with the cristobalite type topology. Figure 1 shows the two networks differentiated by color, being one with red oxygen atoms and cyan metal atoms, and the other with purple oxygen atoms and blue metal atoms.

In order to better understand the features in the $G(r)$, it is necessary to briefly explain the relationship between each PDF peak and the actual atomic distances.

For this reason, the partial PDFs have been calculated [12], based on the Cu2O structure, for the distances $\mathrm{Cu}-\mathrm{Cu}, \mathrm{Cu}-\mathrm{O}$, and $\mathrm{O}-\mathrm{O}$. The same partials have been also calculated using only one network of the two in the structure, to be able to differentiate distances from atoms belonging to the same network from those belonging to different networks. The partial PDFs were weighted by appropriate weighting factors related to scattering properties of the atomic species involved [10]. The results of this can be seen in Figure 2, with the top part showing the partial for one network only and the bottom part showing the partials for the whole structure. Each diagram contains also the total $G(r)$, simulated under exactly the same conditions, for a quicker comparison. A ccording to the figure, the first peak in the PDF represents the $4 \mathrm{M}-0$ distances within the tetrahedron; the second peak corresponds to $12 \mathrm{M}$ M distances, of which 6 are within the same network and the other 6 to interactions between atoms belonging to different networks. The third peak is a combination of $6 \mathrm{M}-0$ distances belonging to interactions on different netw orks and of 0-0 distances in the same network. A summary of this is show $n$ in Table 1. 


\section{Results of the PDF analysis and comparison with EXAFS data}

The position of the first peak in PDF,G(r), constituted by the $4 \mathrm{M}-0$ distances within the tetrahedron, can be used for a direct comparison with EXAFS data [2], which gives the temperature dependence of this $M-0$ bond length. The peak position in the $G(r)$ was evaluated by fitting a Gaussian profile to the data, while the EXAFS data were taken from [2]. As can be seen in Figure 3, the temperature dependence of this distance is the same from both the techniques and its absolute value is very similar for both the techniques, as expected. It is interesting to note that the $\mathrm{Ag}-\mathrm{O}$ bond expands more than $\mathrm{Cu}-\mathrm{O}$ bond. In order to be able to directly compare the results for the two materials, the PDF s were calculated using the same Qmax for both $\left(20 \AA^{-1}\right)$.

Figure 4shows the low-r region of the $G$ ( $r$ ) of copper (top) and silver (bottom) oxides at selected temperatures. A s can be seen from the figure, the first peak is very sharp for both the samples and its shape does not change with temperature, meaning that the 4 distances are still all equal with raising temperature, i.e. there is no measurable distortion of these bond-lengths in the tetrahedron. The positions of the other peaks are not so straightforward to understand and to compare with EXAFS results, due to their composite nature. For example, the second peak (at about $3 \AA$ for $\mathrm{CH}_{2} \mathrm{O}$ and $3.3 \AA$ for $\mathrm{Ag}_{2} \mathrm{O}$ ) comes from contributions from interactions from atoms in the same network and in different networks, while the third one (at about $3.5 \AA$ for $\mathrm{Cu}_{2} \mathrm{O}$ and $4 \AA$ for $\mathrm{Ag}_{2} \mathrm{O}$ ) is a combination of $\mathrm{M}-\mathrm{O}$ and $\mathrm{O}-\mathrm{O}$ interactions. These different contributions may have different behavior with temperature (as al ready demonstrated by EXAFS for the second shell [2]), and therefore care should be employed in comparing results regarding these PDF peaks.

We now look at the behavior of the PDF of the two oxides with temperature in more detail. 


\section{$\underline{4.2 \mathrm{Cu}_{2}} \underline{\mathrm{O}}$}

Figure 4(upper part) shows selected $\mathrm{G}(\mathrm{r})$ of $\mathrm{Cu}_{2} \mathrm{O}$ at different temperatures. B esides what was al ready said about the first peak, let us now look at the second peak ( $6+6 \mathrm{Cu}$-Cu distances): the peak intensity and the peak shape change rapidly with temperature, producing a broader and less intense peak at higher temperatures. In general, the reasons for peak broadening and reduced peak intensity can be found in a purely dynamic disorder (thermal effect), or in geometric distortions (static disorder) that lead to a spread of distances, hence in a broader peak in $G(r)$. A combination of the two effects is also possible. However, the variations in the PDF are far larger than expected for a pure thermal effect $\left(U_{\text {iso }}\right.$ for the PDF measured at 300 $\mathrm{K}$ was $0.015 \AA^{2}$ for copper and $0.018 \AA^{2}$ for oxygen, and still the fit was rather poor $(\mathrm{Rw}=0.181)$. In Figure 5 the $\mathrm{G}(\mathrm{r}) \mathrm{s}$ of the $\mathrm{Cu}_{2} \mathrm{O}$ structure was cal culated with different sets of thermal parameters,similar to those obtained from Rietveld analysis of the same data. The thermal parameters used were: $\left.U_{\text {iso }}(C u)=U_{\text {iso }}(0)=0.005 \AA^{2}, \mathrm{ii}\right) U_{\text {iso }}(C u)=U_{\text {iso }}(0)=0.007 \AA^{2}$, iii) $U_{\text {iso }}(C u)=U_{\text {iso }}(0)=0.009 \AA^{2}$, iv $) U_{\text {iso }}(C u)=U_{\text {iso }}(0)=0.011 \AA^{2}$. The simulations were made with Qmax $=20 \AA^{-1}$. Two main observation can be made from the comparison between the experimental and the simulated data: 1) the decrease in intensity of the third peak is much larger in the experimental PDF than in the simulated PDF; 2) in the third peak a shoulder starts to appear on the high $\mathrm{r}$ side at about $200 \mathrm{~K}$, and further develops at $300 \mathrm{~K}$. This shoulder is not an artefact from the Fourier transform procedure: various checks were made by FT the data with different Qmax, and the shoulder never disappeared. The third peak is dominated by $6 \mathrm{Cu}-0$ distance between atoms belonging to different networks as shown in Figure 2.These effects on the PDF can be due to a distortion in the tetrahedral units, with the solid angle of the tetrahedron changing, and thus producing two different $\mathrm{Cu}$ - $\mathrm{Cu}$ distances. 
This may affect the structure, at least locally, causing the development of the shoulder in the high-r region of the third peak (two different $\mathrm{Cu}-\mathrm{O}$ distances).

\section{$\underline{4.3 \operatorname{Ag}_{2}} \underline{\mathrm{O}}$}

Figure 4 (lower part) shows selected $\mathrm{G}(\mathrm{r}) \mathrm{s}$ of $\mathrm{Ag}_{2} \mathrm{O}$ at different temperatures. Even at the lowest temperature ( $10 \mathrm{~K}$ ), the second peak in the $G(r)$ is almost of the same height as the first one, and the broadening (and decrease in intensity) of the second and third peak is much faster with temperature than for copper oxide. Shoulders appear on both side of the second peak, while the shoulder on the high $r$ side of the third peak is al ready present at $10 \mathrm{~K}$ and grows very fast with temperature, becoming soon more intense than the original distance at about 4 $\AA$ (or moving to higher $r$ with temperature). The origin of these effects on the PDF peaks may be related, also in this case, to a distortion in the tetrahedral units spreading locally in the structure. A structural refinement of the $G(r)$ with PDF gui [12] starting from the undistorted crystal structure of $\mathrm{A} \mathrm{g}_{2} \mathrm{O}$ taken from literature [13], showed that, even at the lowest temperature measured, there were some discrepancies between the "crystallographic" structure and the PDF data (Figure 6). A s can be seen in the figure, the low-r region (below 8-10 $\AA$ ) shows a larger difference curve, revealing the presence of distortions in the local region unexplained by the crystallographic model used. As it can be seen in the figure, the fit in the higher $r$ region proves to be much more satisfactory, showing that the distortions tend to affect the structure locally, within a few coordination shells. In the case of copper oxide, on the other hand, the PDF can be fitted with very good results by using the "crystallographic" structure, at least up to the temperature at which the first distortion starts to appear. The effect, however, is much smaller than in the case of silver oxide, as it can be clearly evinced from the bottom part of Figure 6 . 


\section{Discussion: dynamic disorder vs static disorder}

The results of the comparison between EXAFS and diffraction allow a better understanding of the dynamics of the cuprite structure, showing that neither the $\mathrm{Cu}-\mathrm{O}$ bond nor the $\mathrm{Ag}-\mathrm{O}$ bond are strong enough to form structural units behaving rigidly with temperature [1]. This was also confirmed by inelastic neutron scattering and lattice dynamics calculations [14]. The tetrahedral units tend to deform with temperature, and a certain degree of static disorder is present in the silver oxide structure. M oreover, M ittal and coworkers [14] showed that Cu-0 and $\mathrm{Cu}-\mathrm{Cu}$ bonds are stiffer than $\mathrm{Ag}-\mathrm{O}$ and $\mathrm{Ag}-\mathrm{Ag}$, as al ready evidenced by the larger displacement correlation function found for copper oxide first and second coordination shells [1], [2]. The atom dynamics is almost fully understood: what needs developing and further study is the possible effect of static disorder on the vibrational properties of these materials, and hence on its thermal expansion behavior.

The analysis of the temperature dependent PDF for copper and silver oxides illustrates the presence of geometric distortions in the structure of both oxides that develop with temperature, although starting at different temperatures in the two cases. For copper oxide, the distortion appears for the first time at around $200 \mathrm{~K}$, corresponding to the inversion in the thermal expansion behavior. The presence of this distortion is not in contradiction with the fact that $\mathrm{Cu}_{2} \mathrm{O}$ A D Ps showed a $0 \mathrm{~K}$ intercept compatible with zero point motion, as the deformation begins at high temperature, and no sign of static disorder is present in the low temperature region [6]. In $\mathrm{Ag}_{2} \mathrm{O}$, on the other hand, probably the same tetrahedral distortion appears at very low temperature (it is present even at $10 \mathrm{~K}$ ), confirming the strong contribution of static disorder to the A PDs at low temperature in silver oxide. These distortions become more distinct and a further spread in distances can be seen in the PDF at 
higher temperatures, clear signs of a larger degree of deformation in the structure. The specific nature of these distortions can only be supposed at present, as further analysis is necessary in order to better characterize which atoms are involved and how the structure evolves with temperature. Past studies can provide a good starting point, especially EXA FS data on the different thermal behavior of $M-M$ distances contributing to the second shell. This can play a key role in understanding if the distortion comes from a bending of the $\mathrm{M}-\mathrm{M}$ bond, i.e. a change in the solid angle of the tetrahedral units or from a shortening of the distance between the two networks. What is clear from PDF analysis is that the four M-O bonds within the tetrahedron all remain equal with temperature for both the oxides. M oreover, a comparison between the shape of the first peak compared to the others shows that in the experimental PDF (Figure 4) the first peak is much sharper than the others, while it is not in the simulated ones (Figure 5), where motion correlations are neglected [15], [16]. This confirms the results of the EXAFS-diffraction approach [1], [2], as well as those from lattice dynamics calculations [14]. From these preliminary results, it is still not clear which is the relationship of the structural distortions with the thermal behavior of the two oxides, but there seems to be a correlation between the appearance of the first signs of distortion in $\mathrm{Cu}_{2} \mathrm{O}$ and the inversion temperature (at $200 \mathrm{~K} \mathrm{Cu}_{2} \mathrm{O}$ starts to expand), so copper oxide thermal behavior is not coming only from normal atom dynamics, as supposed until now. The structural distortions in silver oxide are much more evident even at very low temperature and suggest that the local structure has lower symmetry than the average structure. This can certainly play a role in the thermal expansion of the structure, when coupled with the strong transverse vibrations of bridging atoms typical of this structure, but also can play a role in the appearance of the phase transition at low temperature, observed in other $\mathrm{Ag}_{2} \mathrm{O}$ samples. $\mathrm{A}$ 
more detailed study of the PDF evolution with temperature is necessary to better understand the nature of the distortions and their relationship with the thermal behavior of the materials. 


\section{Tables}

Table 1 - Summary of the relationship between interatomic distances and PDF peaks: in the line with "same" one can find interactions between atoms belonging to the same network, in the with "other" one can find interactions between atoms belonging to different networks.

\begin{tabular}{|l|l|l|l|l|l|}
\hline Distance & $1.8 \AA$ & $3 \AA$ & $3.5 \AA$ & $4.2 \AA$ & $4.6 \AA$ \\
\hline M-M & & SAME+OTHER & & OTHER & \\
\hline M-0 & SA M E & & OTHER & & SAME \\
\hline $0-0$ & & & SAME & & \\
\hline
\end{tabular}




\section{Figures}

Figure 1 - Sketch of the cuprite structure: the two different interpenetrating netw orks can be clearly distinguished by color, being one with red oxygen atoms and cyan metal atoms, and the other with purple oxygen atoms and blue metal atoms.

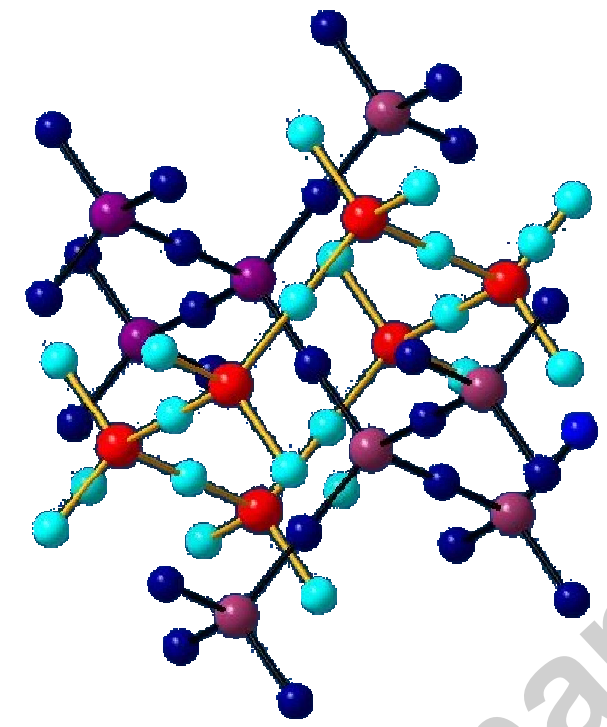


Figure 2 - Partial PDFs for $\mathrm{Cu}-\mathrm{Cu}, \mathrm{Cu}-\mathrm{O}$ and $\mathrm{O}-\mathrm{O}$ bonds in the cuprite structure. The upper part of the figure shows the partial PDFs from just one of the two cuprite networks. The lower part of the figures shows the partial PDFs for the whole structure.
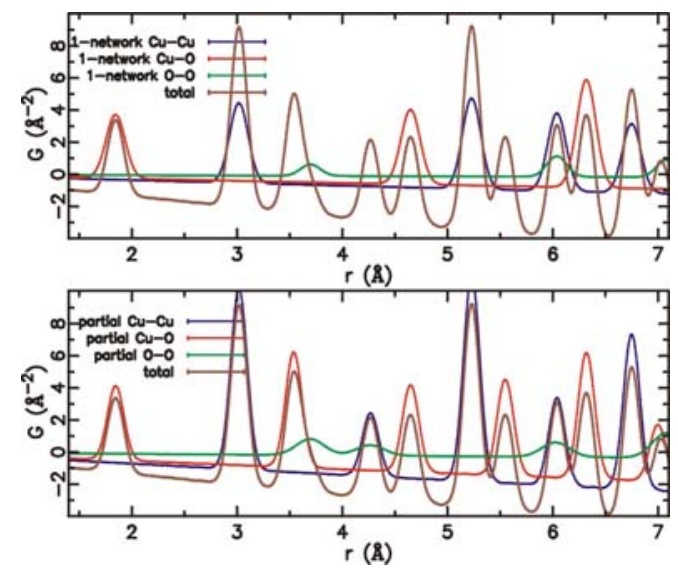
Figure 3 - Comparison between the thermal expansion of the $\mathrm{M}-\mathrm{O}$ bond (first shell) as measured by EXAFS and PDF. The EXAFS data are taken from [2]. The lines are best fit lines for PDF data only, to make the graph more readable. Filled symbols (red in colour) are from the PDF, open symbols are from EXA FS. Silver oxide results are plotted as triangles and cuprite as circles.

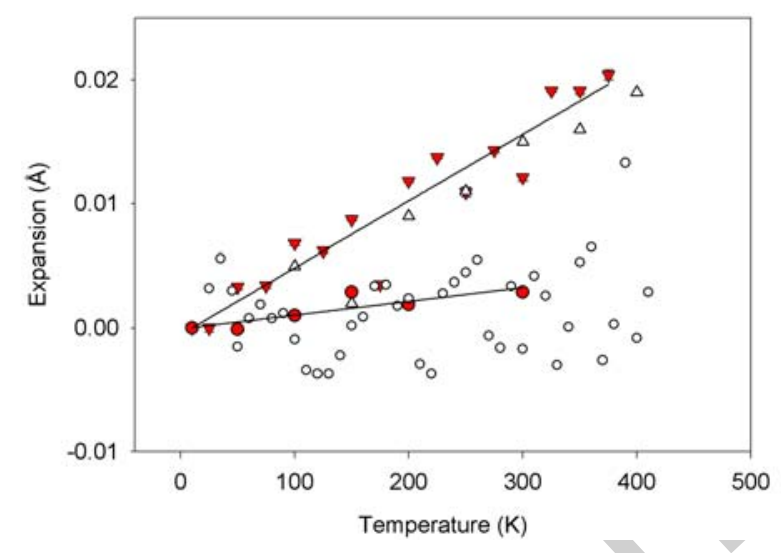


Figure 4 - Comparison of the first three PDF peaks for $\mathrm{Cu}_{2} \mathrm{O}$ and $\mathrm{Ag}_{2} \mathrm{O}$ at selected temperatures between $10 \mathrm{~K}$ and $300 \mathrm{~K}$. For both the oxides the $\mathrm{G}(\mathrm{r})$ were obtained with Qmax $=20 \AA^{-1}$, for a reasonable comparison.
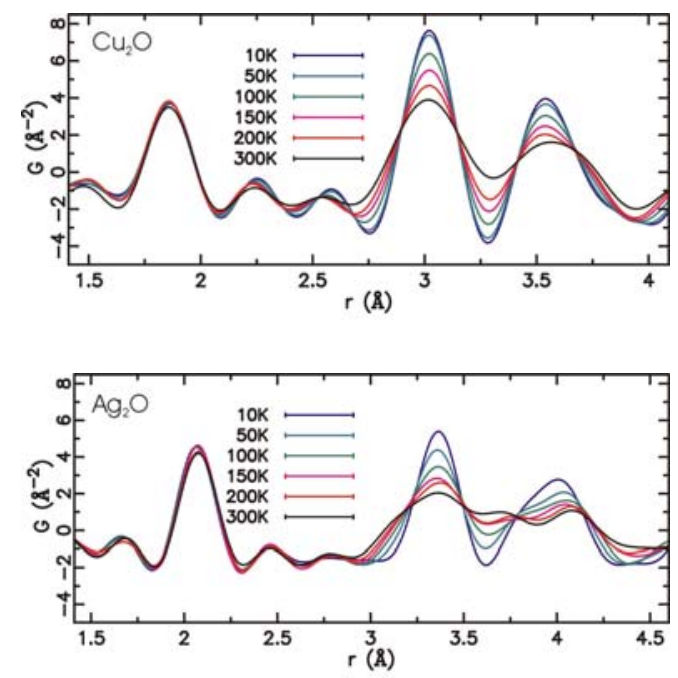
Figure 5 - Effects of thermal factors on the simulated PDF of the $\mathrm{Cu}_{2} \mathrm{O}$ structure, with i) $U(C u)=U(0)=0.005 \AA^{2}$, ii) $U(C u)=U(0)=0.007 \AA^{2}$, iii) $U(C u)=U(0)=0.009 \AA^{2}$, iv $)$ $U(C u)=U(0)=0.011 \AA^{2}$. The simulations are made with $Q \max =20 \AA^{-1}$. These results can be compared with the experimental PDFs shown in Fig. 4.

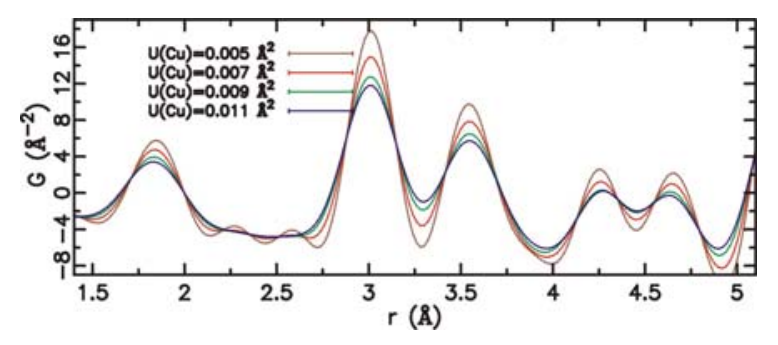


Figure 6 - PDF fits of the cuprite structure. The top part shows the fit of $\mathrm{Ag}_{2} \mathrm{O}$ at $\mathrm{T}=10 \mathrm{~K}$, and the bottom part shows the fit of $\mathrm{Cu}_{2} \mathrm{O}$ at $\mathrm{T}=300 \mathrm{~K}$. The red curve represents the best fit: for $\mathrm{Ag}_{2} \mathrm{O}$ isotropic thermal factor for $\mathrm{Ag}$ and $\mathrm{O}$ equal to $0.012 \AA^{2}$ were used, while for $\mathrm{Cu}_{2} \mathrm{O}$ isotropic thermal factors were refined. The blue dots represent the data points for $\mathrm{Q} \max =20$ $\AA^{-1}$. The green curve underneath the graph represents the difference between the experimental and the calculated $G(r)$.

$\mathrm{Ag}_{2} \mathrm{O}, 10 \mathrm{~K}$

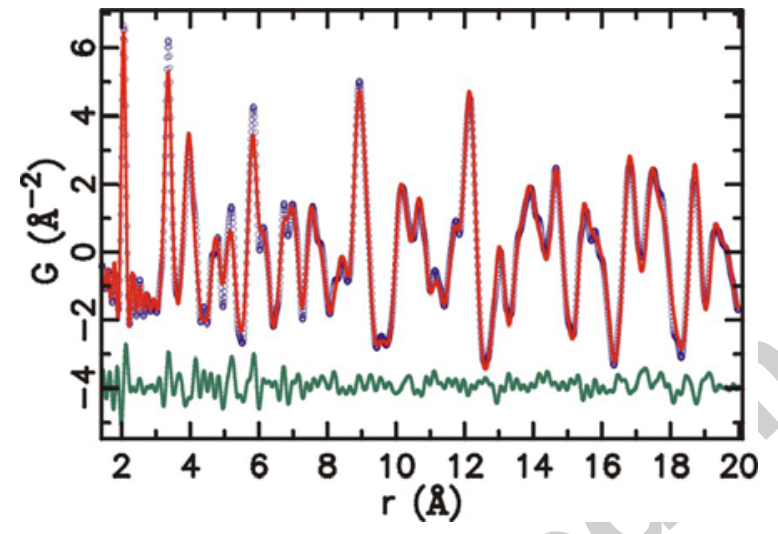

$\mathrm{Cu}_{2} \mathrm{O}, 300 \mathrm{~K}$

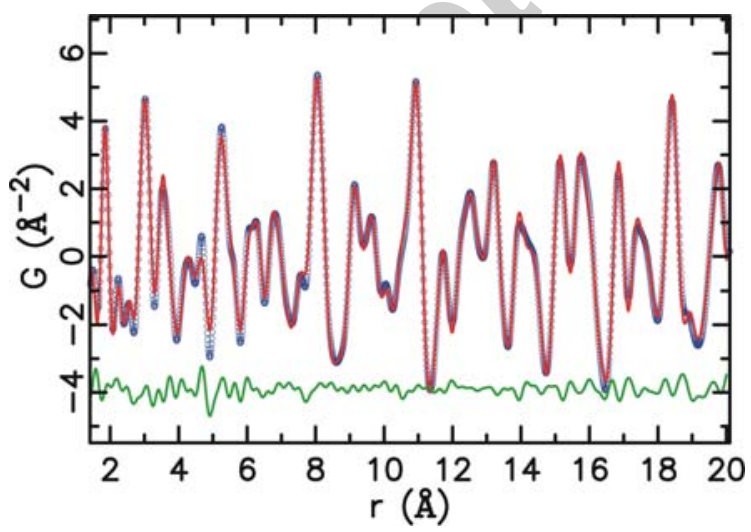




\section{Acknowledgements}

The authors would like to thank ISIS for providing the beam time at GEM (experiment number 510070), and P.G. Radaelli (ISIS) for his help during data collection. M D and GA would also like to thank W. I. F. David (ISIS) for sharing some of his beam time, and for many helpful discussions. MD's work in the Billinge group was funded by the US National Science Foundation through grant DM R-0703940.

\section{References}

1. G. A rtioli, M. Dapiaggi, P. Fornasini, A. Sanson, F. Rocca and M. M erli, Negative thermal expansion in cuprite-type compounds: A combined synchrotron XRPD, EXAFS, and computational study of Cu2O and A g20, J ournal of Physics and Chemistry of Solids 67 (2006), 1918-1922.

2. A. Sanson, F. Rocca, G. Dalba, P. Fornasini, R. Grisenti, M. Dapiaggi and G. A rtioli, N egative thermal expansion and local dynamics in Cu20 and A g20, Physical Review B: Condensed $M$ atter and M aterials Physics 73 (2006), 214305/1-214305/13.

3. T.A. M ary, J.S.O. Evans, T. Vogt and A.W. Sleight, Negative Thermal Expansion from 0.3 to 1050 K elvin in ZrW 208, Science 272 (1996), 90-92.

4. D. Cao, F. B ridges, G.R. K owach and A.P. Ramirez, Frustrated soft modes and negative thermal expansion in ZrW 208, Physical R eview L etters 89 (2002), 215902.

5. D. Cao, F. B ridges, G.R. Kowach and A.P. Ramirez, Correlated atomic motions in the negative thermal expansion material ZrW 208 a local structure study, Physical Review $B$ : Condensed $M$ atter and $M$ aterials Physics 68 (2003), 014303.

6. M. Dapiaggi, W. Tiano, G. A rtioli, A. Sanson and P. Fornasini, The thermal behavior of cuprite: an XRD-EXAFS combined approach, Nuclear Instruments \& M ethods in Physics Research, Section B: B eam Interactions with M aterials and A toms 200 (2003), 231-236.

7. A.C. Hannon, Results on disordered materials from the general materials diffractometer, GEM , at ISIS, Nuclear Instruments \& M ethods in Physics Research, Section A : A ccelerators, Spectrometers, Detectors, and A ssociated Equipment 551 (2005), 88-107.

8. W. Tiano, 2002, Laurea Thesis.

9. B.J. Kennedy, Y. K ubota and K. K ato, N egative thermal expansion and phase transition behaviour in A g20, Solid State Communications 136 (2005), 177-180. 
10. T. Egami and S.J.L. Billinge, Underneath the Bragg peaks: structural analysis of complex materials. Pergamon M aterials Series, ed. R.W . Cahn. V ol. 7. 2003: Pergamon.

11. P.F. Peterson, M. Gutmann, T. Proffen and S.J.L. Billinge, PDFgetN : A user-friendly program to extract the total scattering structure function and the pair distribution function from neutron pow der diffraction data, J ournal of A pplied C rystallography 33 (2000), 1192.

12. C.L. Farrow, P. Juhas, J.W. Liu, D. Bryndin, J. B loch, T. Proffen and S.J.L. B illinge, PDFfit2 and PDF gui: Computer programs for studying nanostructure in crystals, J ournal of Physics: Condensed M atter 19 (2007), 335219.

13. P. Niggli, Die K ristallstruktur einiger Oxyde I, Zeitschrift fuer K ristallographie, K ristallgeometrie, K ristall physik, K ristallchemie 57 (1922), 253-299.

14. R. M ittal, S.R. Chaplot, S.K. M ishra and P.P. B ose, Inelastic neutron scattering and lattice dynamical calculation of negative thermal expansion compounds $\mathrm{Cu} 2 \mathrm{O}$ and A g20, Physical Review B: Condensed M atter and M aterials Physics 75 (2007), 174303(1)-174303(8).

15. I.K. J eong, R.H. Heffner, M.J. Graf and S.J.L. Billinge, Lattice dynamics and correlated atomic motion from the atomic pair distribution function, Physical Review B: Condensed M atter and M aterials Physics 67 (2003), 104301.

16. I.K. J eong, T. Proffen, F. M ohiuddin-J acobs and S.J.L. Billinge, M easuring correlated atomic motion using X -ray diffraction, J ournal of Physical Chemistry A 103 (1999), 921-924. 